\title{
Proposal of Indonesia Seismic Hazard Deaggregation Maps for Sumatra, Indonesia
}

\author{
Achmad Fauzi ${ }^{1}$, Usama Juniansyah Fauzi ${ }^{2}$ Hendriyawan $^{2}$, Wayan Sengara ${ }^{2}$ and Masyhur Irsyam ${ }^{2}$ \\ 1. Faculty of Civil Engineering and Earth Resources, University of Malaysia Pahang, Pahang 26300, Malaysia \\ 2. Faculty of Civil and Environmental Engineering, Bandung Institute of Technology, Bandung 40132, Indonesia
}

\begin{abstract}
The new method for determining ground-motion parameters in the Indonesian Earthquake Resistant Building Code SNI (Indonesia National Standard) 03-1726-2012 has significant changes than the previous code. The maps of mean and modal of magnitude and distance presented here are intended to convey information about the distribution of probabilistic seismic sources and to provide prescriptions or suggestions for seismic sources to use in developing artificial ground motion in building design or retrofit projects. This paper presents deaggregation of Indonesia Seismic Hazard Map 2010 for Sumatra. Deaggregation for 0.2-s and 1.0-s pseudo SA (spectral acceleration) is performed for $10 \% \mathrm{PE}$ (probability of exceedance) in 50 years (475-year mean return period) and $2 \% \mathrm{PE}$ in 50 years (2,475-year mean return period). The information of deaggregation analysis can and perhaps should be considered in a complex seismic-resistant design decision-making environment.
\end{abstract}

Key words: Seismic hazard deaggregation, 3D seismic sources, seismic sources contribution, Indonesia Building Code.

\section{Introduction}

The new Indonesia Seismic Hazard Maps for revising the previous map in SNI 03-1726-2002 was published in July 2010 [1-3] as based for next edition of SNI-03-1726-2012. Seismic source model used in hazard maps was developed based on various publications, previous researches, and the latest information that have been summarized and integrated by Team for Revision of Seismic Hazard Maps of Indonesia. Seismic sources were represented by subduction, fault and background zones that were represented by three-dimensional models. The new maps were developed based on PSHA (probabilistic seismic hazard analysis) method proposed by Cornell [4].

A principal advantage of the probabilistic method is combining all the possible earthquakes affecting the site [4]. Unfortunately, the integrative process of PSHA also has some disadvantages. One major

Corresponding author: Usama Juniansyah Fauzi, M.Sc., research field: geotechnical earthquake engineering. E-mail: juniansyahfauzi@gmail.com. weakness is the lost concept of real earthquake. To resolve this problem, deaggregation of seismic hazard can be used to display the contributions to a hazard value of fundamental parameters such as magnitude and distance.

The Team for Revision of Seismic Hazard Maps of Indonesia has produced several new seismic hazard maps for Indonesia. The final model and maps were issued in 2010 as summary of Study Team for Revision of Seismic Hazard Maps of Indonesia [3]. The method and results given in this summary are the basis for BSN (National Standardization Agency) recommended seismic design provisions for the Indonesian Earthquake Resistant Building Code SNI (Indonesia National Standard) 03-1726-2012. This summary presented seismic hazard maps computed for sites on bed rock (shear wave velocity, $V_{s}=760$ $\mathrm{m} / \mathrm{s}^{2}$ ) at the $10 \%$ PE (probability of exceedance) in 50 years and $2 \% \mathrm{PE}$ in 50 years.

Seismic hazard parameters for subduction considered recurrence relationship that includes truncated exponential model and pure characteristic 
model. For fault sources, truncated exponential model and characteristic model with aleatory uncertainty in the magnitude using a normal distribution sigma of \pm 0.12 were used. For background source, only truncated exponential model was used in the development of hazard maps. Several attenuation functions including NGA (next generation attenuation) and logic-tree were used. The detail information on seismic source models and seismic parameters for development seismic hazard maps appear in Refs. [5, 6].

This paper, in conjunction with Team for Revision of Seismic Hazard Maps of Indonesia, intends to convey information about the distribution of probabilistic seismic sources with explaining typical values of earthquake magnitude and distance that are making the largest contributions to the seismic hazard maps. Identifying the predominant sources of hazard will lead to better choices for the design earthquake's characteristics. Performing deaggregations at more than one period will help to determine if one source dominates at all periods and clarify the need for one, or more than one, design earthquake [7].

\section{PSHA and Deaggregation of PSHA}

PSHA was developed by Frankel et al. [8] which is based on the probability concept developed by Cornell [4]. It is assumed that the earthquake magnitude $M$, and distance $R$, are continuous independent random variables. In general, form of total probability theorem can be expressed in the following:

$$
H(a)=\sum v_{i} \iint P[A>a \mid m, r] f_{M i}(m) f_{R i} \mid M_{i}(r, m) \mathrm{d} r \mathrm{~d} m \text { (1) }
$$
where, $v_{i}$ is annual rate of earthquakes (with magnitude higher than some threshold value of $M_{o i}$ ) in source $I$, and $f_{M i}(m)$ and $f_{R i \mid M i}(r, m)$ are probability density functions on magnitude and distance, respectively. $P[A>a \mid \mathrm{m}, r]$ is the probability that an earthquake of magnitude $m$ at distance $r$ produces a peak acceleration $A$ at the site that is greater than $a$.

Software for PSHA used in this study was obtained from the USGS (United States of Geological Survey)
[9]. A site spacing of $0.1^{\circ}$ in latitude and longitude and area between $94^{\circ} \mathrm{E}$ to $142^{\circ} \mathrm{E}$ longitudes and $12^{\circ} \mathrm{S}$ to $8^{\circ} \mathrm{N}$ latitude were used in the analysis. The ground motion parameters obtained from this study were computed for sites on bed rock $\left(V_{s}=760 \mathrm{~m} / \mathrm{s}^{2}\right)$. The verification seismic models and parameters in this research with Team for Revision of Seismic Hazard Maps of Indonesia are shown in Ref. [6].

The method of deaggregation of hazard is to separate the contributions into a limited number of bins of (annular) distance, magnitude, and ground-motion uncertainty [8]. For this research, the distance annular width, $\Delta R$, is $5 \mathrm{~km}$ and the magnitude bins is 0.5 . For subduction sources, the maximum considered source to site distance is $1,000 \mathrm{~km}$. For fault and background sources, the maximum considered source to site distance is $200 \mathrm{~km}$. Using PSHA result, the relative contributions of sources to the overall hazard results at the given site are deaggregated in different types of bins to determine and understand. The integration of the PSHA is carried out and the final results are presented often in terms of 3D $M-R-\varepsilon$ (magnitude-distance-epsilon) bins or even geographical deaggregation (4D) [10]. Typical deaggregation result can be seen in Fig. 1.

The mean distance and mean magnitude presented here are the weighted mean values of $R$ and $M$, respectively, for all sources that contribute to hazard at each grid location, for instance, the mean value of magnitude and distance in Fig. 1. The modal distance and modal magnitude are the $(R, M)$ pair having the largest contribution in the hazard deaggregation at each grid location, for instance, the peak value of magnitude and distance in Fig. 1. The maps develop using the grid increment of $0.1^{\circ}$ in both latitude and longitude and in area between $94^{\circ} \mathrm{E}$ to $142^{\circ} \mathrm{E}$ longitudes and $12^{\circ} \mathrm{S}$ to $8^{\circ} \mathrm{N}$ latitude so that deaggregations seismic hazards are performed for more than 96,600 sites. Software for deaggregation PSHA used in this study was obtained from the USGS. 


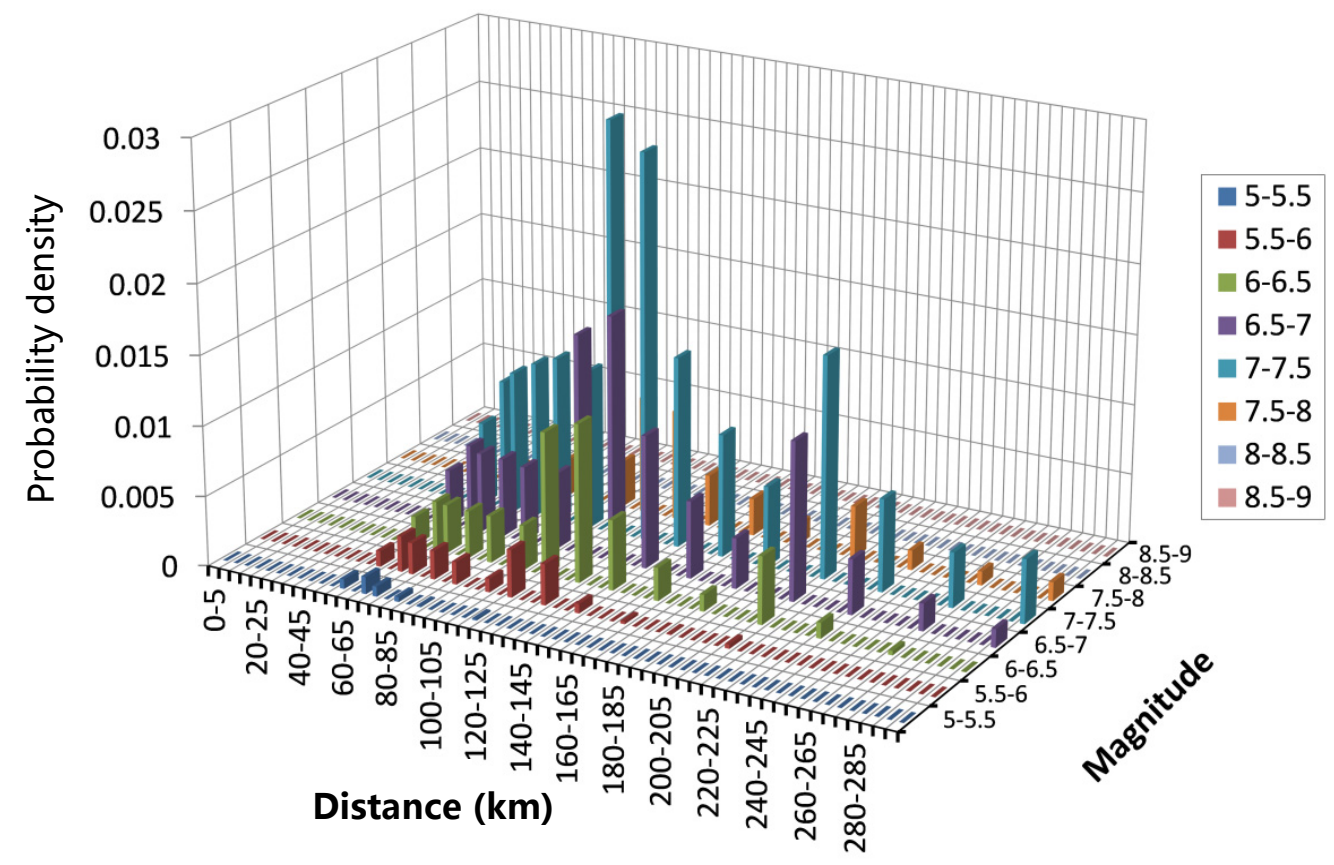

Fig. 1 Deaggregation hazard result of 500 years return period for Palembang $(T=0.2 \mathrm{~s})$.

3. Earthquake Catalog, Seismotectonic Model, Recurrence Relations and Ground Motion Prediction Equation

Seismic parameters used in this study were derived from published journals, proceedings, previous researches conducted by team members, and latest information obtained during this study. This study has then compiled and integrated previous and current studies. Earthquake source parameters were determined based on earthquake catalog, geological, and seismological information of active faults. The earthquake catalog covered earthquake period between 1900 to 2009 , relocated catalog by the year 2005 , and area between $90^{\circ} \mathrm{E}$ to $145^{\circ} \mathrm{E}$ longitudes and $15^{\circ} \mathrm{S}$ to $15^{\circ} \mathrm{N}$ latitudes.

Seismic sources use recurrence relationship that includes truncated exponential model, pure characteristic model, and both models. Geometry of fault and subduction were represented by 3D models based on the result of tomography and slip-rates of faults were determined by considering the results of GPS (global positioning system) measurement as shown in Fig. 2. Background source zones were modeled

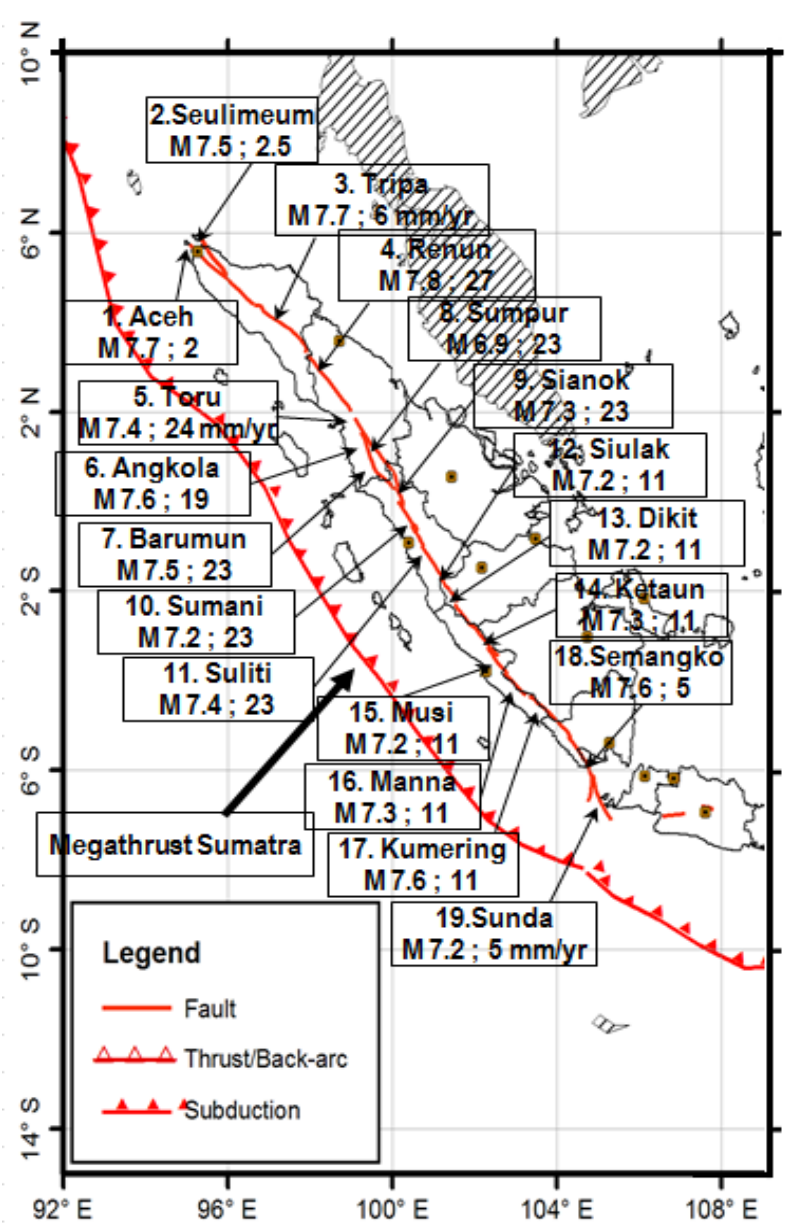

Fig. 2 Seismotectonic model for analysis. 
using gridded seismicity based on spatially smoothed earthquake rates. The earthquake catalog was used for developing gridded seismicity starting from 1900 to 2009 and the updated Engdahl catalog up to 2009 was used for control geometry of subduction [11]. Several well-known attenuation functions were selected in accordance with the mechanism of seismic source including the NGA. Logic tree was also applied to account for epistemic uncertainty including recurrence model, maximum magnitude and several attenuation functions.

\section{Results and Discussions}

One purpose of deaggregation analysis is to find plausible $(R, M)$ pairs from which we can choose accelerograms, $A(t)$, for input to seismic design programs for structural response. The maps of mean and modal magnitude and distance for $10 \% \mathrm{PE}$ in 50 years are shown in Figs. 3-6. Maps of mean and modal magnitude and distance for $2 \% \mathrm{PE}$ in 50 years are shown in Figs. 7-10.

The analysis result showed that the maps of modal results are associated with the highest contribution of earthquake source. In case of areas near the fault $(<$ $200 \mathrm{~km}$ ), magnitude and distance are controlled by fault source. However, in the area located far from the fault source $(>1,000 \mathrm{~km})$, most magnitude and distance are controlled by gridded seismicity source. Then, in the area between $200 \sim 1,000 \mathrm{~km}$, most magnitude and distance are controlled by subduction source. The mean magnitude and distance are associated with the average of contribution from multimodal/multi scenario earthquake. The mean and modal maps showed different values of pair magnitude and distance so that most sites receive contributions from a broad distribution of source magnitudes and distances. There is a discontinuity in the contour in Figs. 6 and 10 in their left upper parts. It is due to higher contribution of Sumatra subduction zone than faults and background zones.

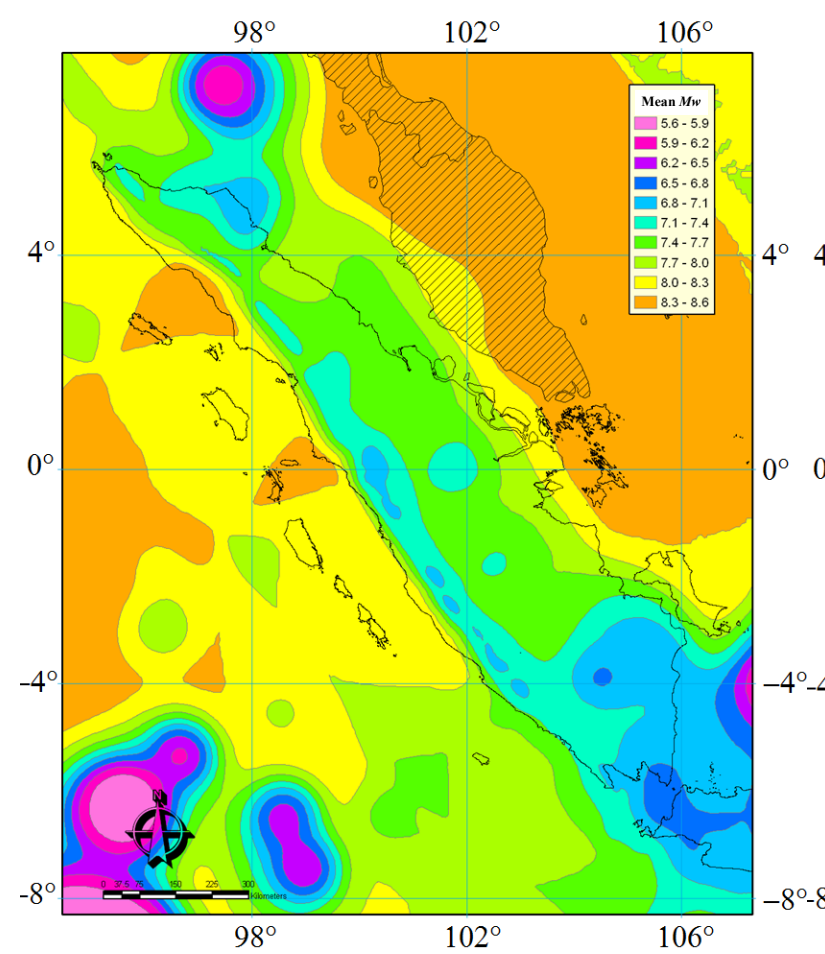

(a)

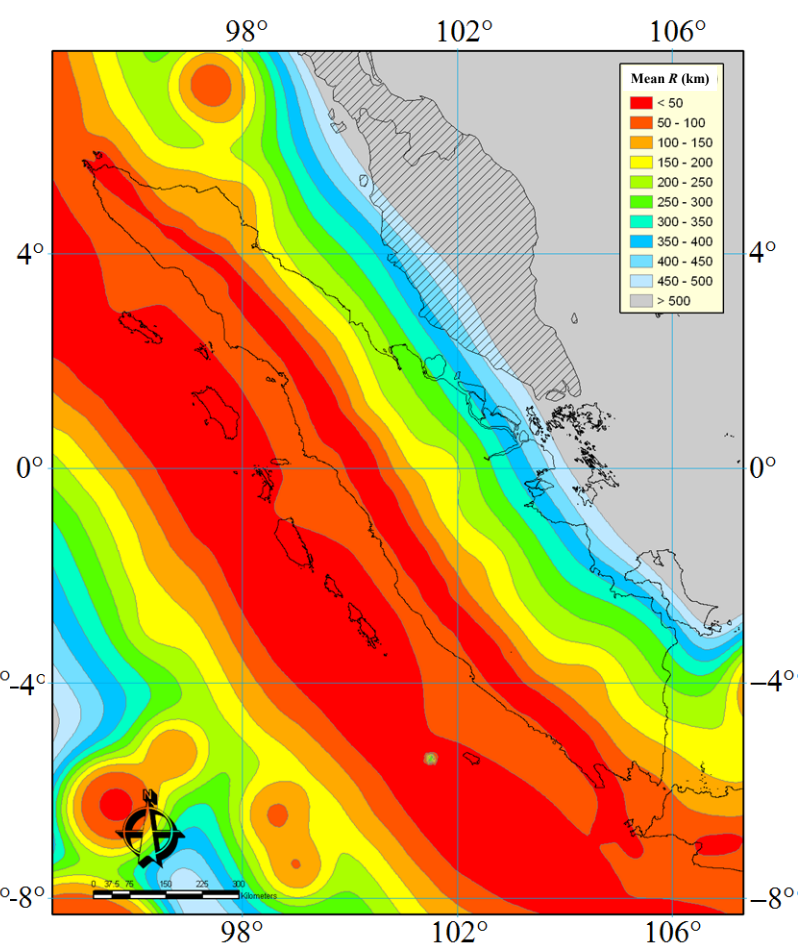

(b)

Fig. 3 Maps of $0.2 \mathrm{~s}$ spectral acceleration of Sumatra for $10 \%$ probability of exceedance in 50 years: (a) mean magnitude; (b) distance. 


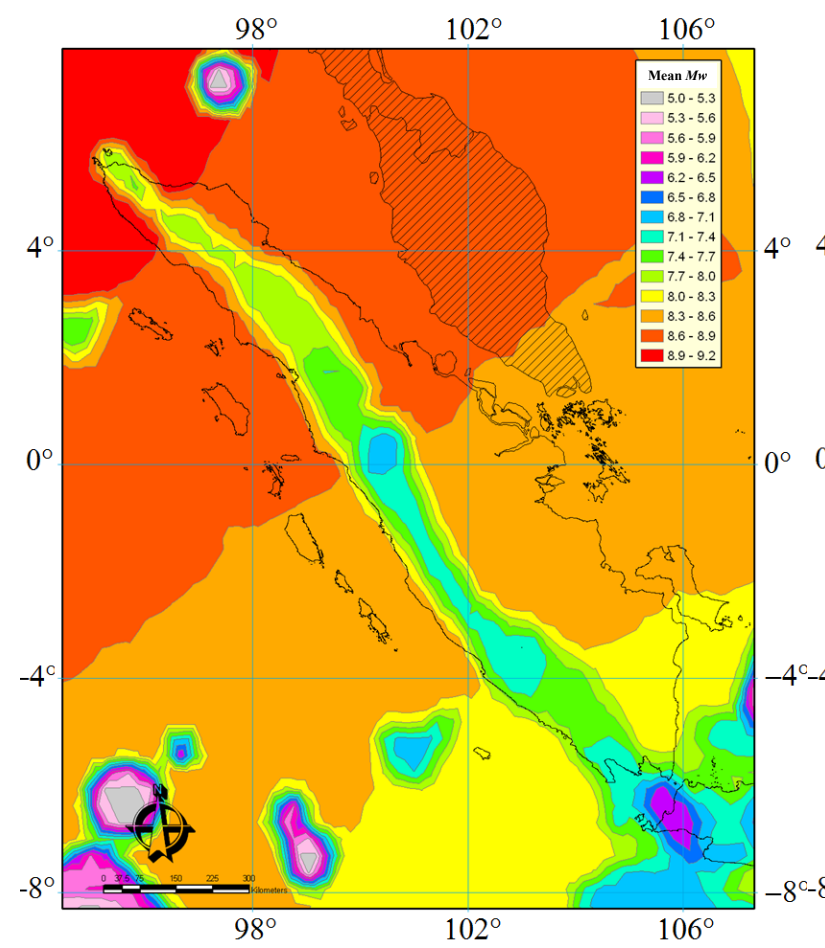

(a)

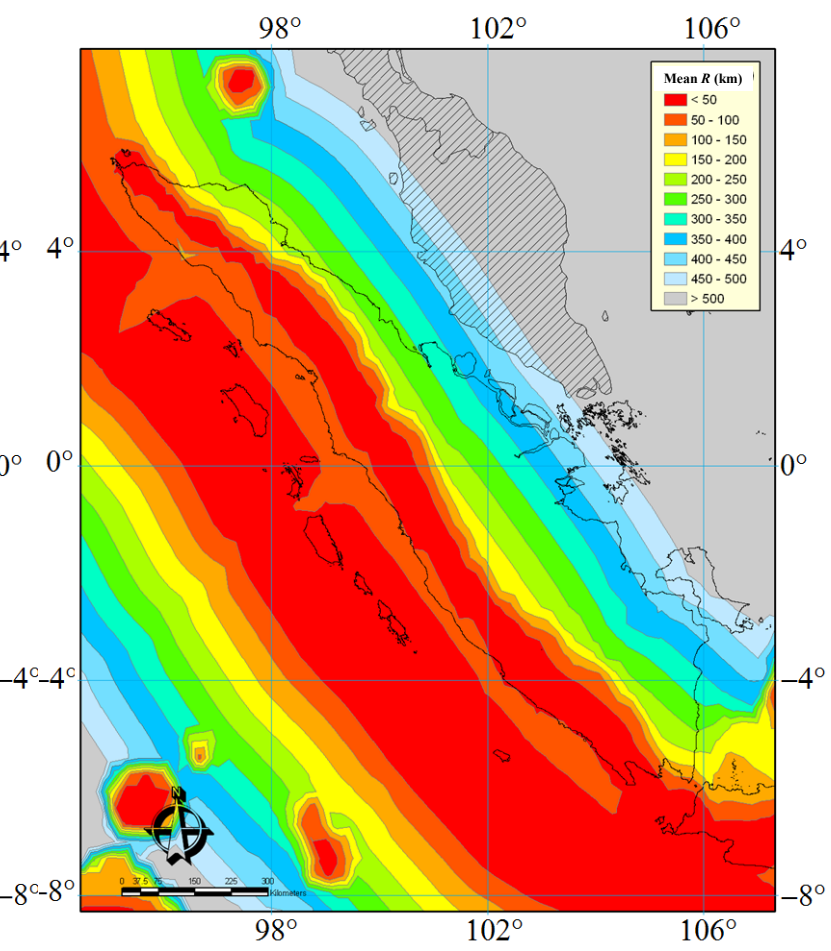

(b)

Fig. 4 Maps of 0.2 s spectral acceleration of Sumatra for $10 \%$ probability of exceedance in 50 years: (a) modal magnitude; (b) distance.

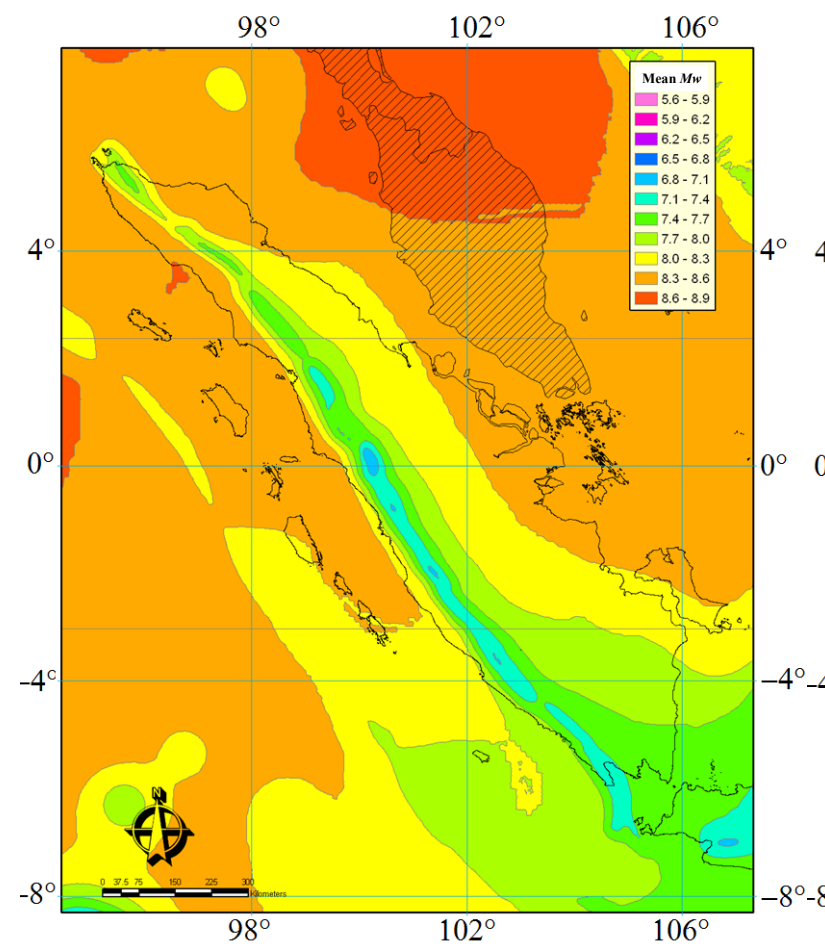

(a)

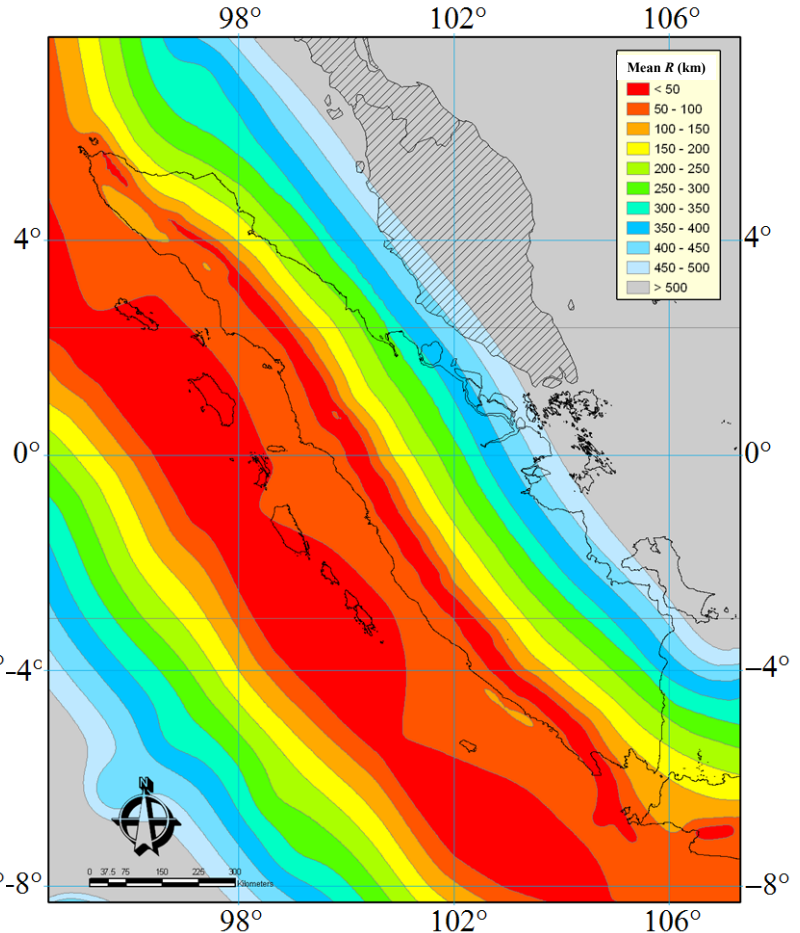

(b)

Fig. 5 Maps of $1.0 \mathrm{~s}$ spectral acceleration of Sumatra for $10 \%$ probability of exceedance in 50 years: (a) mean magnitude; (b) distance. 


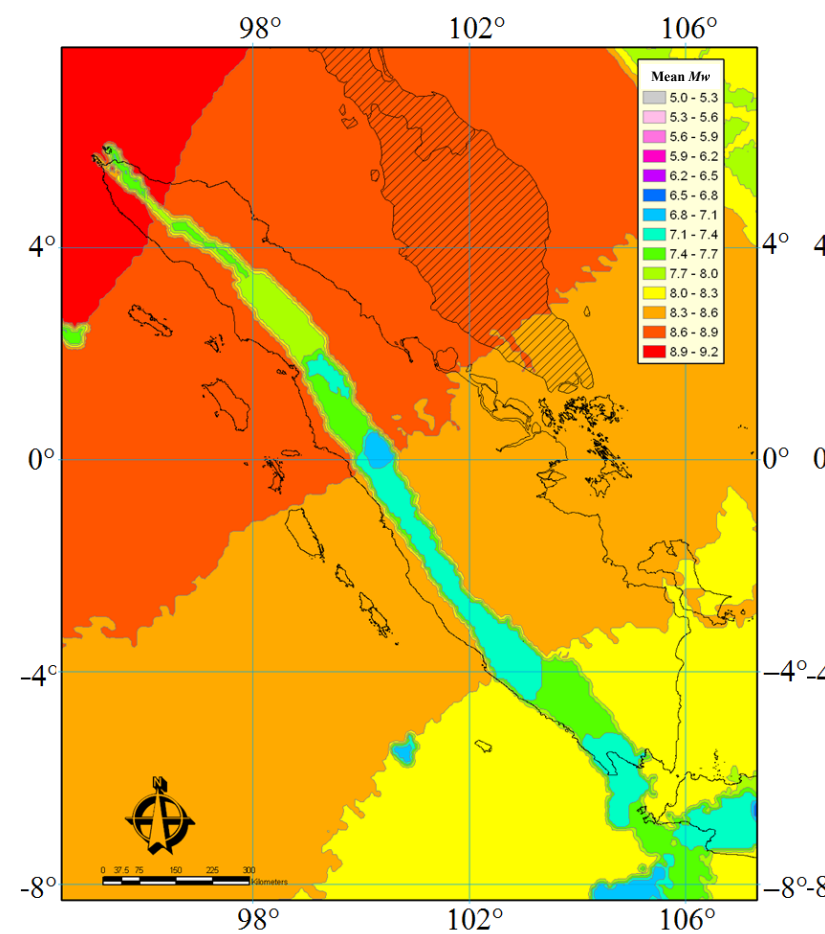

(a)

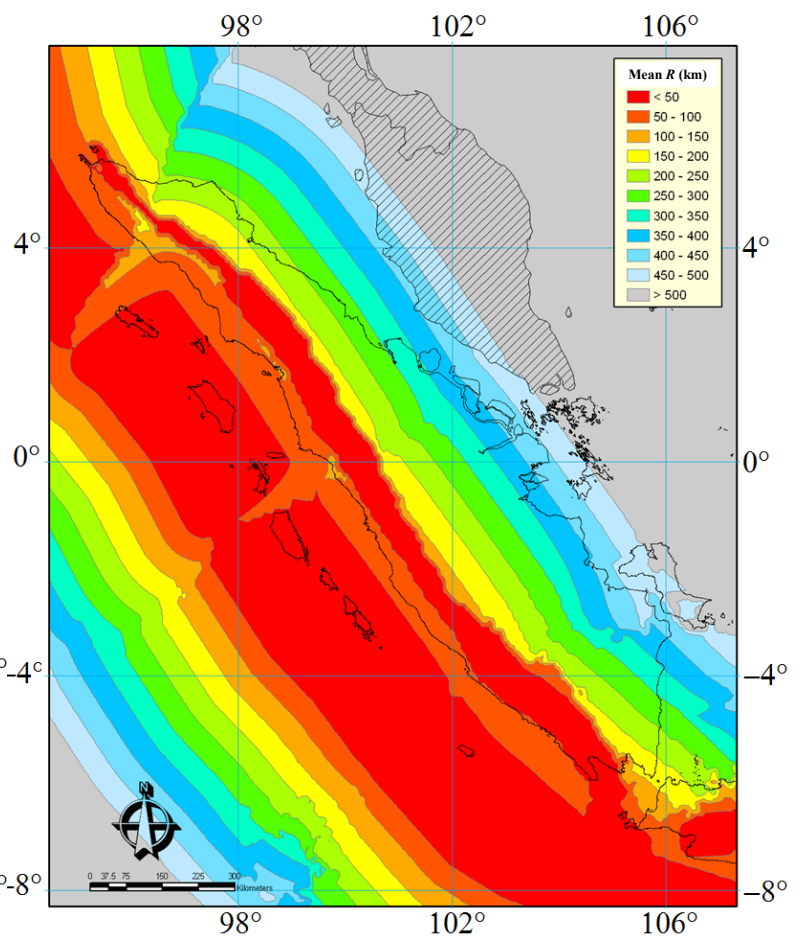

(b)

Fig. 6 Maps of 1.0 s spectral acceleration of Sumatra for $10 \%$ probability of exceedance in 50 years: (a) modal magnitude; (b) distance.

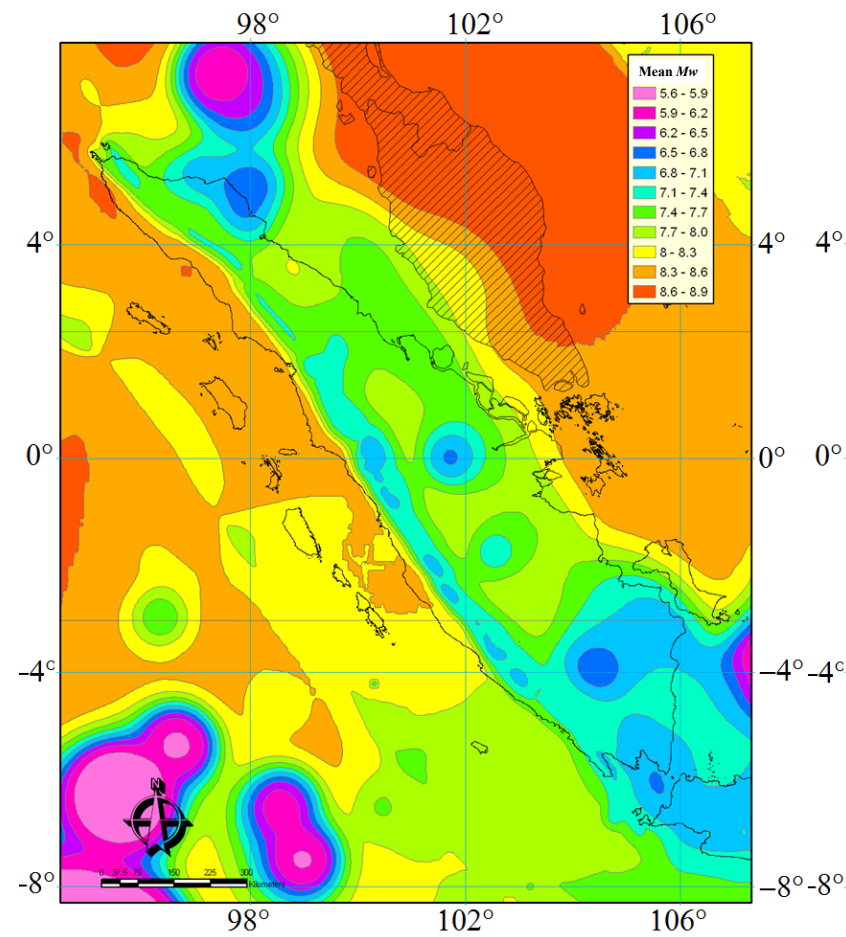

(a)

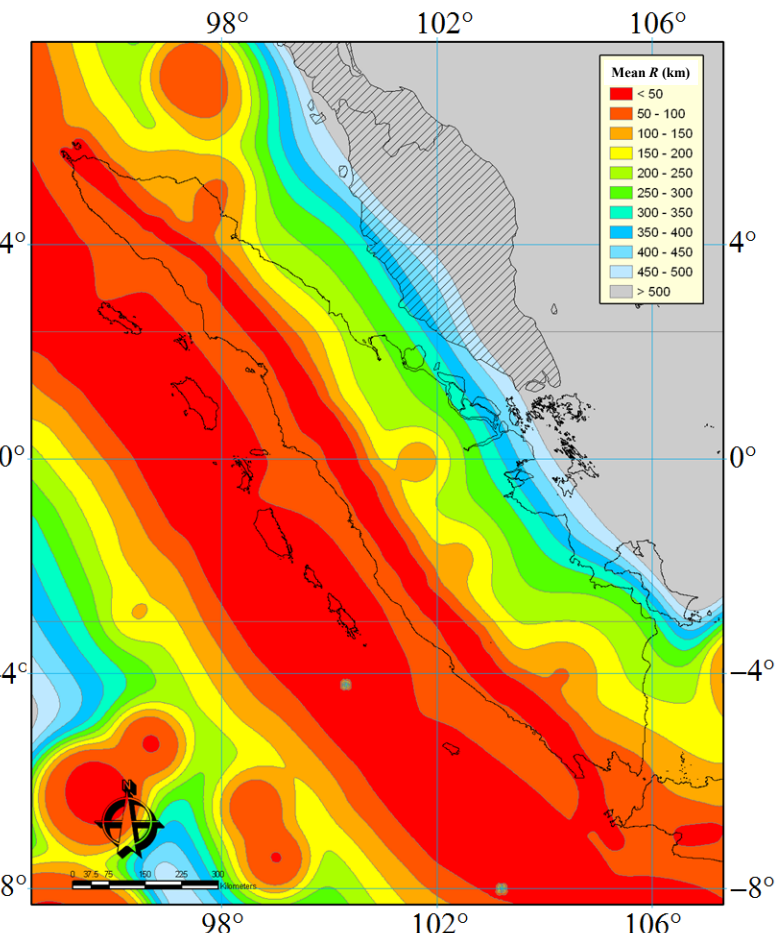

(b)

Fig. 7 Maps of $0.2 \mathrm{~s}$ spectral acceleration of Sumatra for $2 \%$ probability of exceedance in 50 years: (a) mean magnitude; (b) distance. 


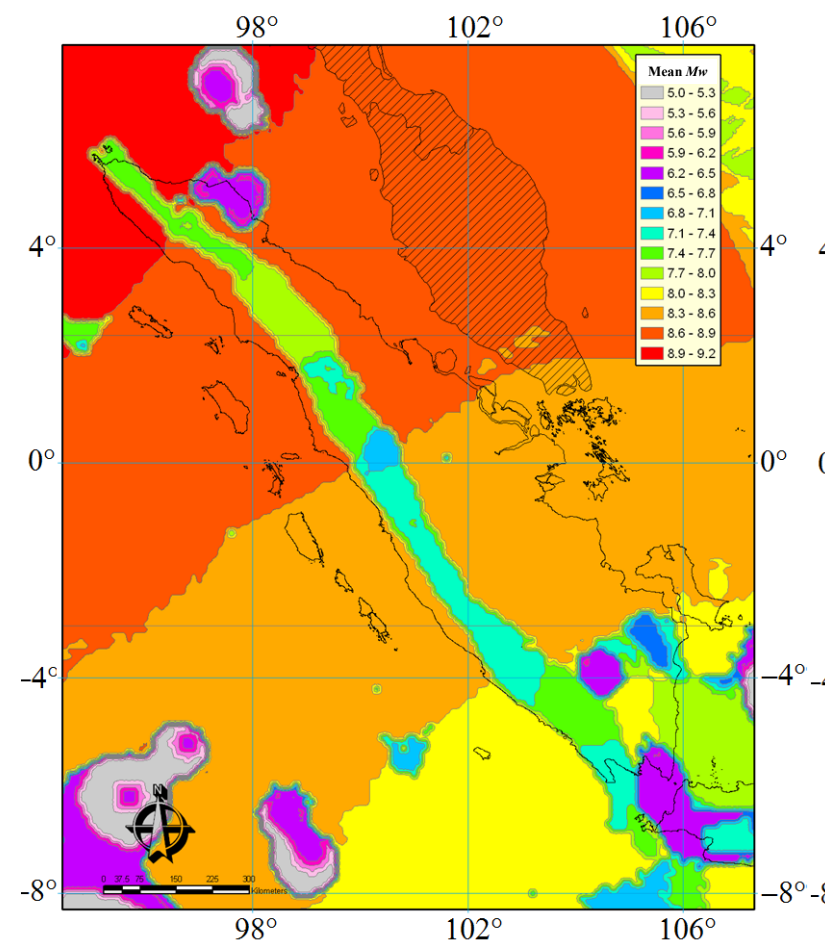

(a)

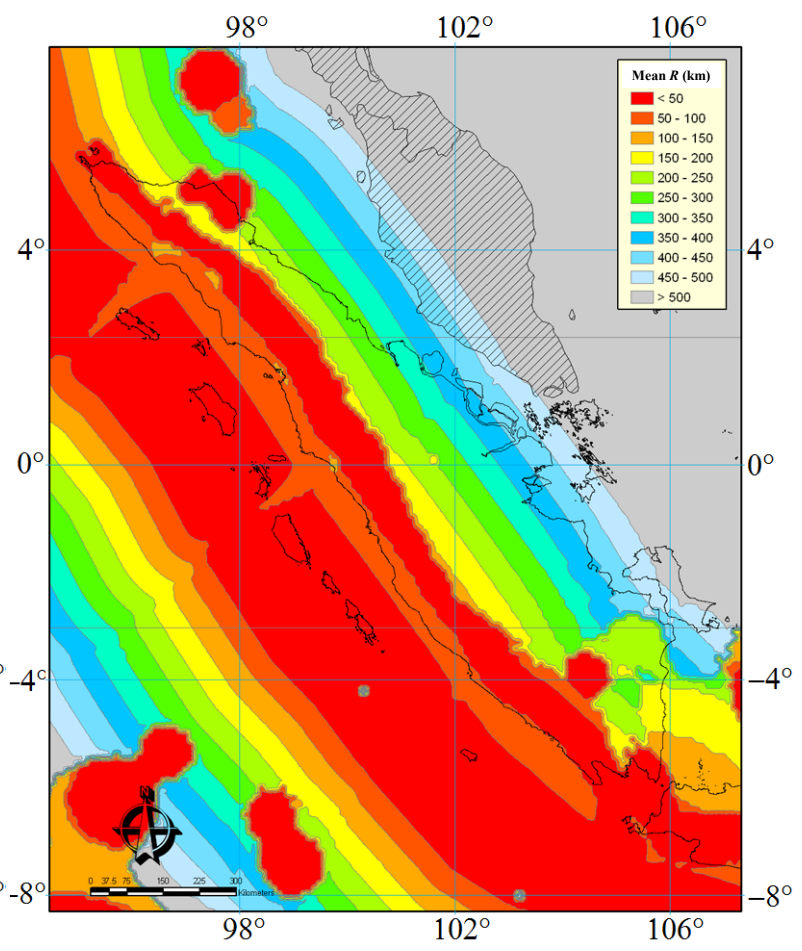

(b)

Fig. 8 Maps of $0.2 \mathrm{~s}$ spectral acceleration of Sumatra for $2 \%$ probability of exceedance in 50 years: (a) modal magnitude; (b) distance.

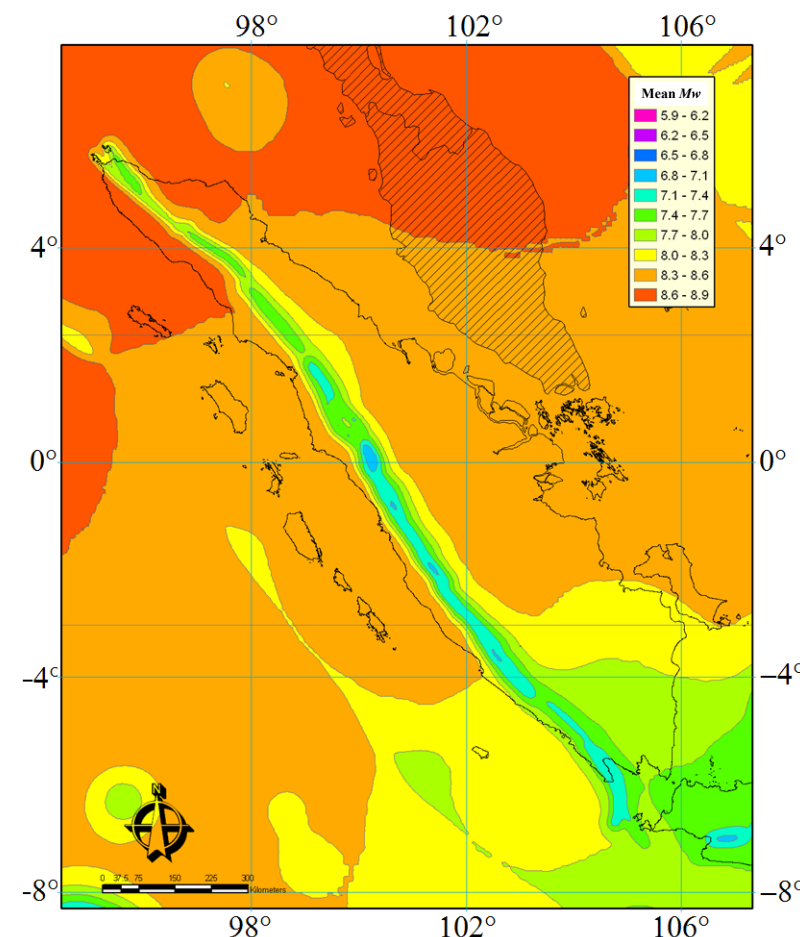

(a)

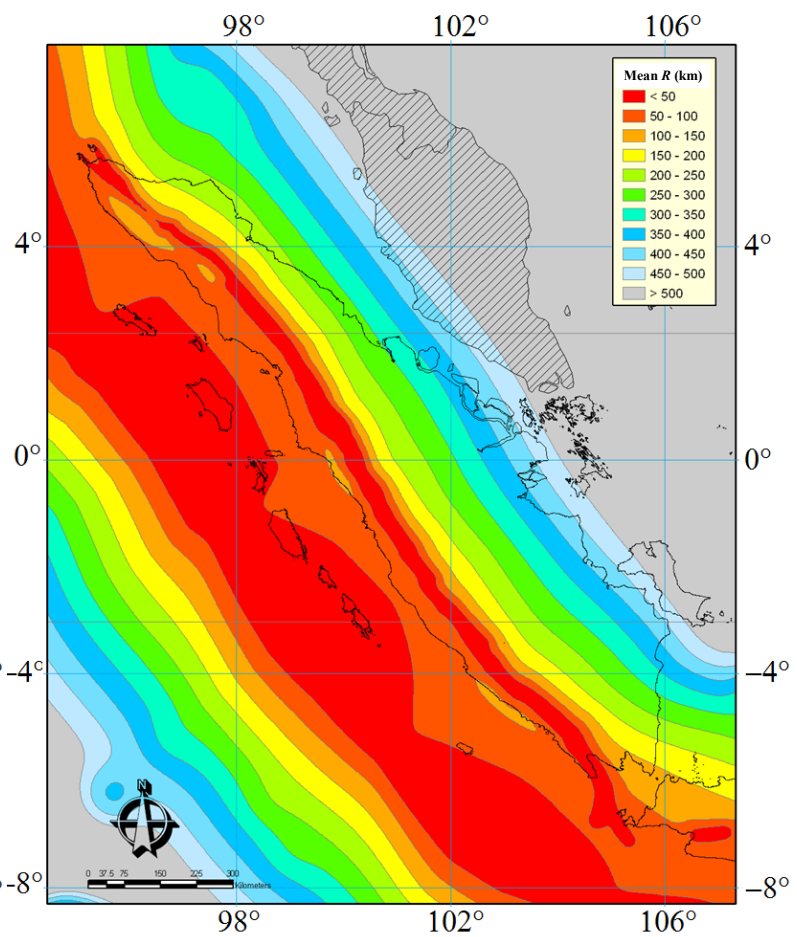

(b)

Fig. 9 Maps of 1.0 s spectral acceleration of Sumatra for $2 \%$ probability of exceedance in 50 years: (a) mean magnitude; (b) distance. 


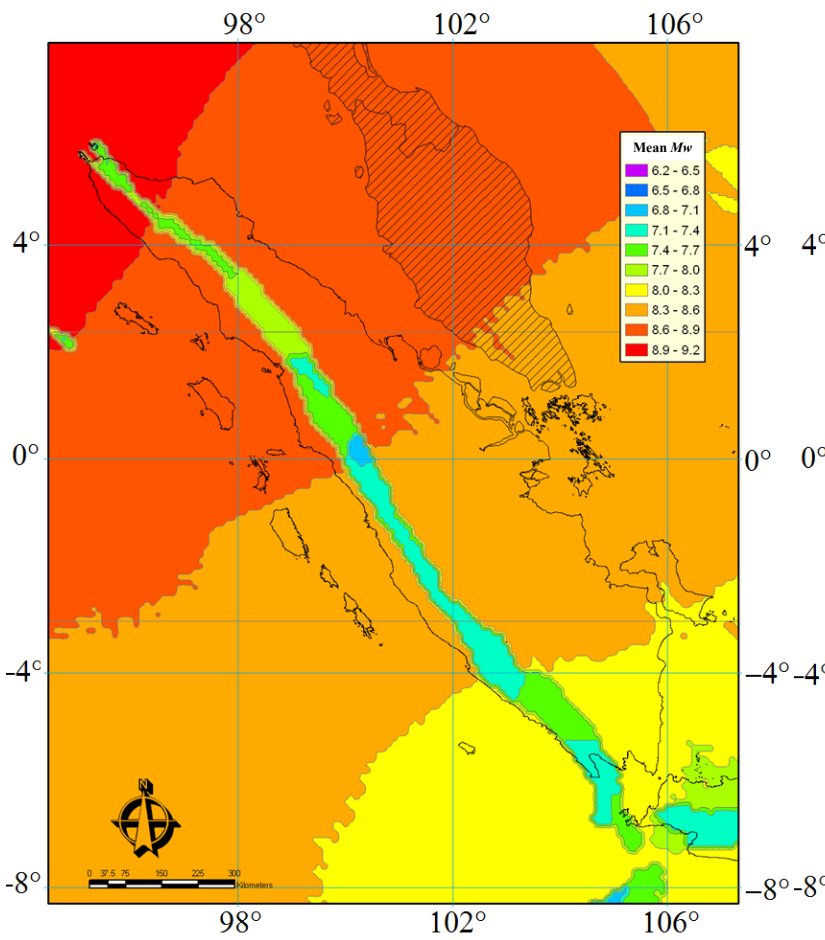

(a)

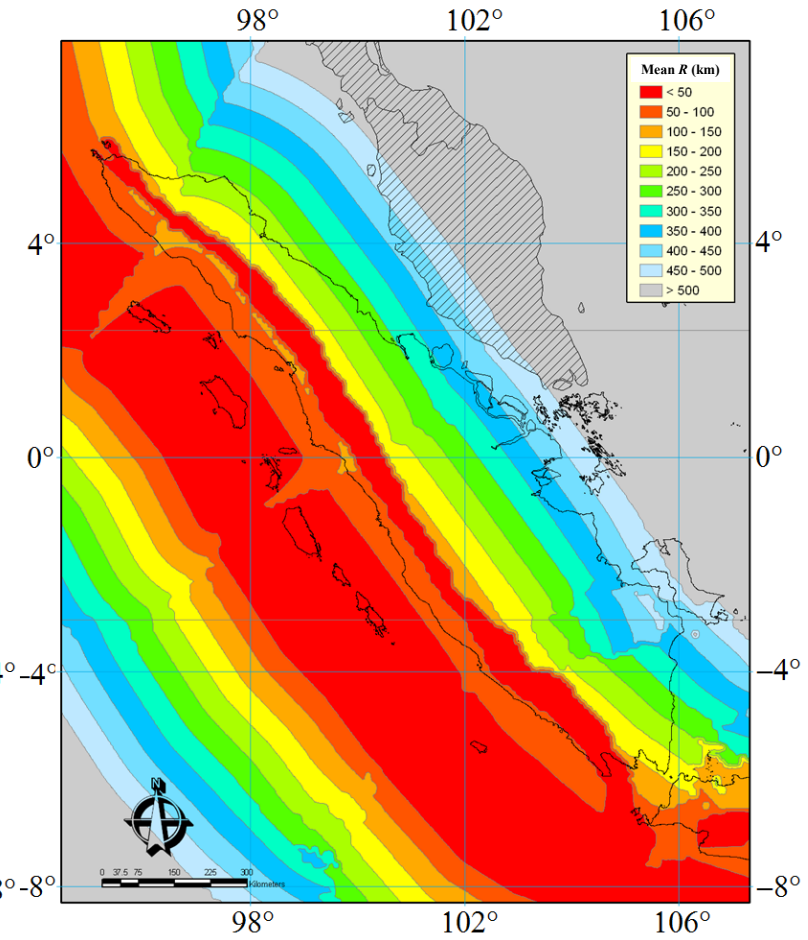

(b)

Fig. 10 Maps of 1.0 s spectral acceleration of Sumatra for $2 \%$ probability of exceedance in 50 years: (a) modal magnitude; (b) distance.

\section{Conclusions}

For most locations, the deaggregation reveals that more than one design earthquake will be required for engineering purposes. The maps of mean and modal of magnitude and distance presented here are intended to convey information about the distribution of probabilistic seismic sources and to provide prescriptions or suggestions for seismic sources to use in building design or retrofit projects. The information of deaggregation analysis can and perhaps should be considered in a complex seismic-resistant design decision-making environment.

\section{Acknowledgments}

The authors wish to show their sincerest gratitude to Team for Revision of Seismic Hazard Maps of Indonesia, for allowing authors to incorporate the valuable data when the team developed new Indonesia Seismic Hazard Maps. The authors are also deeply indebted to USGS (Harmsen, S. D., and Petersen, M.
D.) for providing the authors with technical discussions and the software for PSHA and PSHA deaggregation. Financial support for the research was provided by Bandung Institute of Technology, Indonesia.

\section{References}

[1] Irsyam, M., Asrurifak M., Hendriyawan, H., Budiono, B., Triyoso, W., and Firmanti, A. 2010. "Development of Spectral Hazard Maps for Proposed Revision of Indonesia Seismic Building Code." Geomechanic and Geoengineering 5 (1): 35-47.

[2] Irsyam, M., Asrurifak M., Hendriyawan, H., Budiono, B., Triyoso, W., and dan Hutapea, B. 2008. "Proposal of Indonesia Seismic Hazard Maps with Three Dimensional Earthquake Source Using Probabilistic Method." In Proceeding of Seminar Indonesian Society of Geotechnical Engineering, CD-ROM. (in Indonesian)

[3] Team for Revision of Sesismic Hazard Maps of Indonesia. 2010. Summary of Study. Research report of Ministry of Public Works.

[4] Cornell, C. A. 1968. "Engineering Seismic Risk Analysis." Bulletin of the Seismological Society of America 58 (5): 1583-606. 
[5] Fauzi, U. J. 2011. "Deaggregation Maps of Indonesia with Three Dimensional Earthquake Source Using Probabilistic Method.” Master thesis, Bandung Institute of Technology. (in Indonesian)

[6] Halchuk, A., and Adams, J. 2004. "Deaggregation of Seismic Hazard for Selected Canadian Cities." In Proceeding of 13th World Conference on Earthquake Engineering, No. 2470.

[7] McGuire, R. K. 1995. "Probabilistic Seismic Hazard Analysis and Design Earthquakes: Closing the Loop." Bulletin of the Seismological Society of America 85: 1275-84.

[8] Frankel, A. D., Petersen, M. D., Mueller, C. S., Haller, K. M., Wheeler, R. L., Leyendecker, E. V., Wesson, R. L., Harmsen, S. C., Cramer, C. H., Perkins, D. M., and Rukstales, K. S. 2002. Documentation for the 2002
Update of the National Seismic Hazard Maps. US Geological Survey, Open file report.

[9] Harmsen, S. C., and Frankel, A. 2001. "Geographic Deaggregation of Seismic Hazard in the United States." Bulletin of the Seismological Society of America 91 (1): 13-26.

[10] Engdahl, E. R., Villasenor, A., de Shon, H. R., and dan Thurber, C. H. 2007. "Teleseismic Relocation and Assessment of Seismicity (1918-2005) in the Region of the $2004 \mathrm{Mw}$ 9.0 Sumatra-Andaman and $2005 \mathrm{Mw} 8.6$ Nias Island Great Earthquakes." Bulletin of the Seismological Society of America 97: S43-61.

[11] Harmsen, S. C., Frankel, A. D., and Petersen, M. D. 2003. Deaggregation of US Seismic Hazard Sources: The 2002 Update. US Geological Survey, Open file report. 